\title{
IDENTIFICAÇÃO DE OPORTUNIDADES DE MELHORIA DO DESEMPENHO AMBIENTAL DOS PROCESSOS DE BIODIGESTÃO ANAERÓBIA E INCINERAÇÃO DOS RESÍDUOS SÓLIDOS URBANOS
}

\section{IDENTIFICATION OF PERFORMANCE IMPROVEMENT OPPORTUNITIES OF ENVIRONMENTAL OF THE ANAEROBIC DIGESTION AND INCINERATION PROCESSES OF MUNICIPAL SOLID WASTE}

\section{Luana de Assis Silva ${ }^{1}$, Fábio Rubens Soares ${ }^{2}$; Emília Satoshi Miyamaru $\mathrm{Seo}^{3}$ \\ ${ }^{1}$ Engenheira Ambiental do Centro Universitário SENAC/SP. \\ ${ }^{2}$ Professor e pesquisador do Centro Universitário SENAC. \\ ${ }^{3}$ Professora e pesquisadora do Centro Universitário SENAC e do Instituto de \\ Pesquisas Energéticas e Nucleares - IPEN/CNEN-SP.}

\begin{abstract}
RESUMO
O presente trabalho tem por objetivo identificar as oportunidades para melhoria do desempenho ambiental dos processos de geração de energia pela biodigestão anaeróbia e incineração a partir do tratamento de resíduo sólido urbano - RSU com o uso da ferramenta avaliação do ciclo de vida. Para biodigestão anaeróbia dos RSU a etapa que apresentou impactos mais significativos foi a disposição dos rejeitos em aterro sanitário; enquanto que, a incineração propriamente dita, foi a etapa nos quais os impactos foram mais preponderantes. Os resultados das análises comparativas, apontam para necessidades de melhorias no desempenho ambiental do processo de incineração, pois este se mostrou mais impactante, considerado também, que o processo de incineração apresenta maior eficiência energética. Observou-se que se fazem necessários investimentos em tecnologias que possibilitem a redução desses impactos, para que a incineração seja uma possível solução sustentável para tratamento dos RSU associado à geração de energia, pela sua eficiência tanto para geração de energia, quanto para a redução do volume, massa e periculosidade dos resíduos. Portanto, recomenda-se a utilização das tecnologias de recuperação energética, tais como, incineração, biodigestão e captação e utilização de biogás de aterros, associados à reciclagem, de forma a integrar seu objetivo principal, de tratamento dos resíduos à geração de energia elétrica.

Palavras-chave: Resíduos Sólidos Urbanos. Digestão Anaeróbia. Incineração. Avaliação do Ciclo de Vida.
\end{abstract}

\section{ABSTRACT}

This study aims to identify opportunities for improving the environmental performance of the power generation technologies from the treatment of municipal solid waste - MSW using the tool of the life cycle assessment. The most significant impact was the disposal of waste in landfill; while 
incineration itself was the technology in which the impacts were most prevalent. The results of the comparative analysis, point out the need to improve the environmental performance of the incineration process, as this was more impactful, considering also that the incineration process has greater energy efficiency. It was observed that are necessary investments in technologies that enable the reduction of these impacts, so that incineration is a possible solution for sustainable treatment of MSW associated with power generation, for its efficiency on power generation, and for the reduction of volume, mass and hazardous waste. Therefore, it recommends the use of energy recovery technologies such as incineration, anaerobic digestion and utilization of landfill biogas, associated with recycling to generate electricity from MSW treatment.

Keywords: Municipal Solid Waste. Anaerobic Digestion. Incineration. Life Cycle Assessment.

\section{INTRODUÇÃO}

As fontes renováveis de energia vêm se constituindo como alternativas às fontes tradicionais. Na medida em que apresentam bom desempenho ambiental, e possibilitam a geração distribuída de energia de forma a atender às demandas de áreas isoladas.

$\mathrm{O}$ objetivo do desenvolvimento de fontes alternativas de energia não se limita às preocupações ambientais, mas também o desenvolvimento de tecnologias no país, reduzindo sua dependência das mesmas para produção de energia. Além disso, as novas fontes renováveis têm sido utilizadas para reduzir as diferenças regionais do acesso à energia, pois apesar de seus elevados custos, se comparados às fontes tradicionais, podem se tornar competitivas em comunidades isoladas (COSTA e PRATES, 2005).

O crescimento contínuo e acentuado da população mundial tem tornado o gerenciamento de resíduos um dos principais desafios atuais, tendo em vista a complexidade de se encontrar uma solução para destinação/tratamento dos resíduos, que são gerados em quantidade cada vez mais elevada (SANTOS, 2011). Neste sentido, a incorporação da recuperação energética nas alternativas de destinação dos resíduos resulta na redução no consumo de matéria prima, o aumento da vida útil dos aterros e a diminuição dos custos ambientais, principalmente as emissões de Gases de Efeito Estufa - GEE (MARTINS, 2006).

A energia gerada a partir do tratamento dos Resíduos Sólidos Urbanos (RSU) - resíduos domiciliares e de limpeza urbana - vem se tornando cada vez mais atraente, uma vez que o uso da biomassa e outras fontes renováveis podem reduzir o consumo de combustíveis fósseis e com isso, os impactos causados por queima, contribuindo para que a matriz energética seja mais sustentável (PECORA et al., 2013).

O crescimento nos investimentos em fontes alternativas de energias e a busca pela diversificação da matriz energética resultam em uma tendência no crescimento do potencial de geração de biogás. Dessa forma, a biodigestão anaeróbia dos RSU compõe uma alternativa possível às regiões que necessitam de tratamento de resíduos, por meio do uso de reatores anaeróbios que promovem o saneamento, previne a poluição e a contaminação dos recursos hídricos e do solo, além de se tornar uma fonte de energia (SOUZA et al., 2012).

Neste contexto, a incineração também se apresenta como alternativa ao tratamento de RSU, pois diminui o volume dos resíduos em cerca de $90 \%$ e o peso a $15 \%$, com destaque para a geração de energia, que viabiliza sua implantação sobre o ponto de vista do custo/benefício de sua construção e implantação (MORGADO e FERREIRA, 2006).

Devido a esta tendência, se faz necessária à avaliação do desempenho ambiental destes processos, pelo levantamento dos impactos ambientais, uma metodologia que vem sendo consolidada com uso da ferramenta de Avaliação do Ciclo de Vida - ACV (SANTOS, 2002). Em face de estas considerações, o presente trabalho tem por objetivo identificar as oportunidades para melhoria do desempenho ambiental dos processos de geração de energia pela biodigestão anaeróbia 
e incineração a partir do tratamento de Resíduos Sólidos Urbanos com uso da ferramenta de Avaliação do Ciclo de Vida.

O objetivo do presente estudo é realizar a Avaliação do Ciclo de Vida (ACV) da geração de energia elétrica nos processos de biodigestão anaeróbia e incineração dos RSU. E a sua justificativa encontra-se na necessidade de disponibilização de estudos sobre os impactos ambientais de fontes alternativas de geração de energia.

\section{MATERIAL E MÉTODOS}

A metodologia para a elaboração deste artigo primeiramente consistiu no levantamento de pesquisa bibliográfica, em busca de subsidio para o entendimento dos processos de destinação de RSU por meio da biodigestão anaeróbia e da incineração, bem como da ferramenta de Avaliação do Ciclo de Vida (ACV). Posteriormente, foi iniciado estudo dos processos de tratamento de resíduos associados à geração de energia e com aplicação da ferramenta Avaliação do Ciclo de Vida, seguindo os princípios e a estrutura apresentados na ABNT ISO 14040 (ABNT, 2009; 2014). De acordo com essas normas, foi realizada a primeira etapa se estabelecendo Definição do Objetivo e Escopo do estudo, de forma a obter sua finalidade e amplitude. Nesta fase, foram determinadas as fronteiras e a unidade funcional consideradas no estudo.

O uso de softwares para ACV auxilia na execução do estudo, principalmente na análise do inventário do processo, na facilidade e na rapidez do processamento dos dados, além de garantir a confiança nos cálculos e obtenção de relatórios mais consistentes. Facilita o gerenciamento dos dados, pois disponibiliza bancos de dados, efetua a avaliação e interpretação de impactos associados aos processos, apresentando os resultados por meio de gráficos e tabelas (RODRIGUES et al., 2008).

A ACV foi desenvolvida com o uso do Software SimaPro 7.2, uma ferramenta para coletar dados e analisar o desempenho ambiental de produtos, processos e serviços, seguindo as recomendações da série ABNT ISO 14040 (ABNT, 2014). Lançado em 1990 e constitui uma ferramenta confiável e flexível usada pelas grandes indústrias, consultorias e universidades em mais de 80 países (ACV BRASIL, 2014). Esse software foi escolhido, pois o Centro Universitário SENAC possui a licença educacional do mesmo, o que facilitou no desenvolvimento. E o banco de dados utilizado para a realização da ACV no foi o Ecoinvent data 2.1 disponível no próprio Software SimaPro.

Os inventários de dados brasileiros publicados na literatura são escassos. Ao realizar um ACV em regiões diferentes a qual foi construído o inventário do processo no banco de dados, se faz necessária avaliação da aplicabilidade desses dados na região, considerando as similaridades e diferenças dos aspectos geográficos e tecnológicos locais (ARAÚJO, 2013). Dessa forma, o que se pretende é realizar uma análise comparativa do desempenho ambiental dos dois processos estudados, com base nos dados secundários obtidos no banco de dados Ecoinvent, que não representam um cenário especificamente brasileiro. $\mathrm{Na}$ análise de inventário, portanto, foram utilizados os dados do Ecoinvent pelo software SimaPro.

Durante a fase de análise de inventário foram elaborados no software os fluxogramas dos processos estudados, contemplando todas as atividades envolvidas e suas entradas e saídas dos processos, subprocessos e suas relações de acordo com as fronteiras previamente determinadas. Para melhor apresentação e compreensão dos processos, posteriormente os fluxogramas foram transcritos no software Microsoft Office PowerPoint 2007.

Após a conclusão dos fluxos, ainda na análise de inventário, houve a necessidade de ajustar os dados das entradas de acordo com a unidade funcional e os fatores de conversão aplicáveis ao cenário brasileiro. Para tal foram necessários cálculos para compatibilização dos dados, tomando como base a unidade funcional de uma tonelada de RSU, porcentagem de orgânicos, porcentagem 
de fase úmida, etc.

$\mathrm{Na}$ sequência, foi realizada a análise dos impactos ambientais de cada processo de tratamento de resíduos associado à geração de energia, no software SimaPro, aplicando a metodologia Norte Americana TRACI - Tool for the Reduction and Assessment of Chemical and other Environmental Impacts, que avalia os impactos ambientais baseando-se nas seguintes categorias de impacto: aquecimento global, acidificação, saúde humana, carcinogênicos, não carcinogênicos, efeitos respiratórios, eutrofização, depleção do ozônio, ecotoxicidade e poluição.

Os resultados gerados no software SimaPro são apresentados em gráficos e tabelas. Para melhor apresentação dos mesmos neste trabalho, posteriormente aos cálculos, os gráficos e tabelas foram transcritos no software Microsoft Office Excel 2007.

A partir dos resultados anteriores, foi realizada uma análise comparativa, cujos impactos ambientais dos dois processos foram analisados. E por fim, os resultados foram interpretados de forma a subsidiar as conclusões e recomendações referentes ao desempenho ambiental dos processos estudados.

Sobre o público-alvo, este consiste em usuários da metodologia da ACV como ferramenta de tomada de decisão para o planejamento e avaliação da viabilidade de implantação de sistemas alternativos para tratamento de resíduos e geração de energia. A unidade funcional deste estudo é a massa de resíduo que deu entrada no processo e está diretamente relacionada a quantidade de energia a ser gerada, e é de uma tonelada.

\section{RESULTADOS E DISCUSSÃO}

As fronteiras adotadas para o estudo contemplam os processos envolvidos a partir da triagem e preparação dos resíduos antes de serem encaminhados ao reator anaeróbio ou incinerador. Desta forma, os processos predecessores, como coleta e transporte dos resíduos, não serão incluídos neste estudo. As fronteiras (Figuras 1 e 2) foram baseadas em referências bibliográficas encontradas e no banco de dados utilizado, contemplando as etapas envolvidas, entradas e saídas incluindo as emissões dos processos.

No processo de biodigestão foram consideradas as etapas de pré-tratamento, digestão dos resíduos orgânicos e o pós-tratamento do material digerido e do líquido gerado durante o adensamento (GOMES, 2010). Os rejeitos segregados na ATT e nos processos posteriores são destinados à disposição em aterro sanitário com sistema de captação do lixiviado e dos gases gerados.

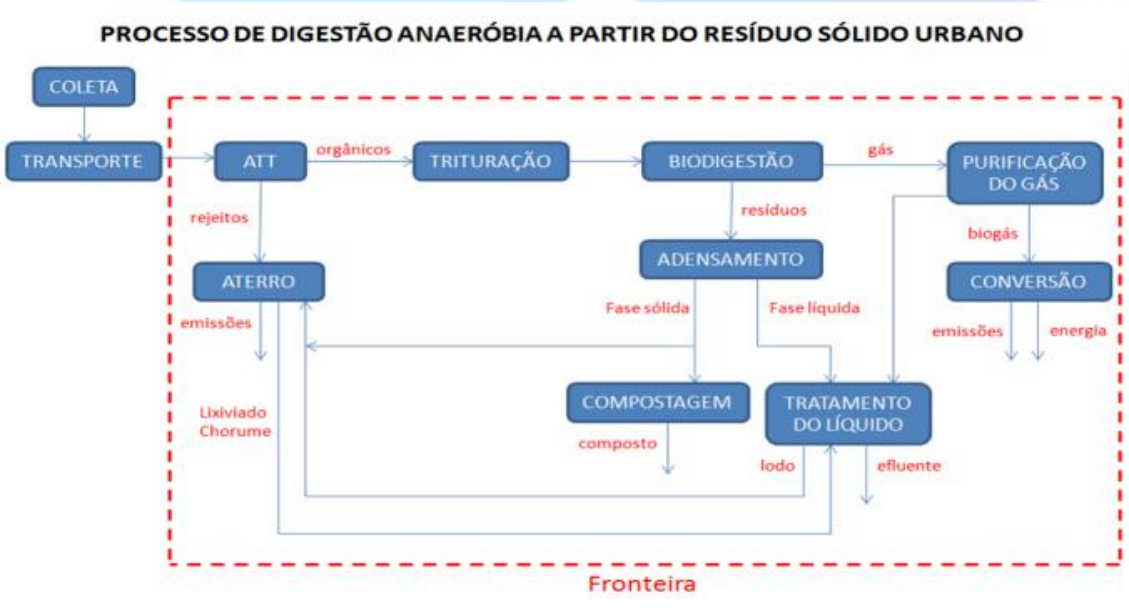

* ATT - Área de Triagem e Transbordo

Figura 1. Fluxograma do processo e fronteira do estudo para biodigestão 


\section{PROCESSO DE INCINERAÇÃO DOS RESÍDUO SÓLIDO URBANO}

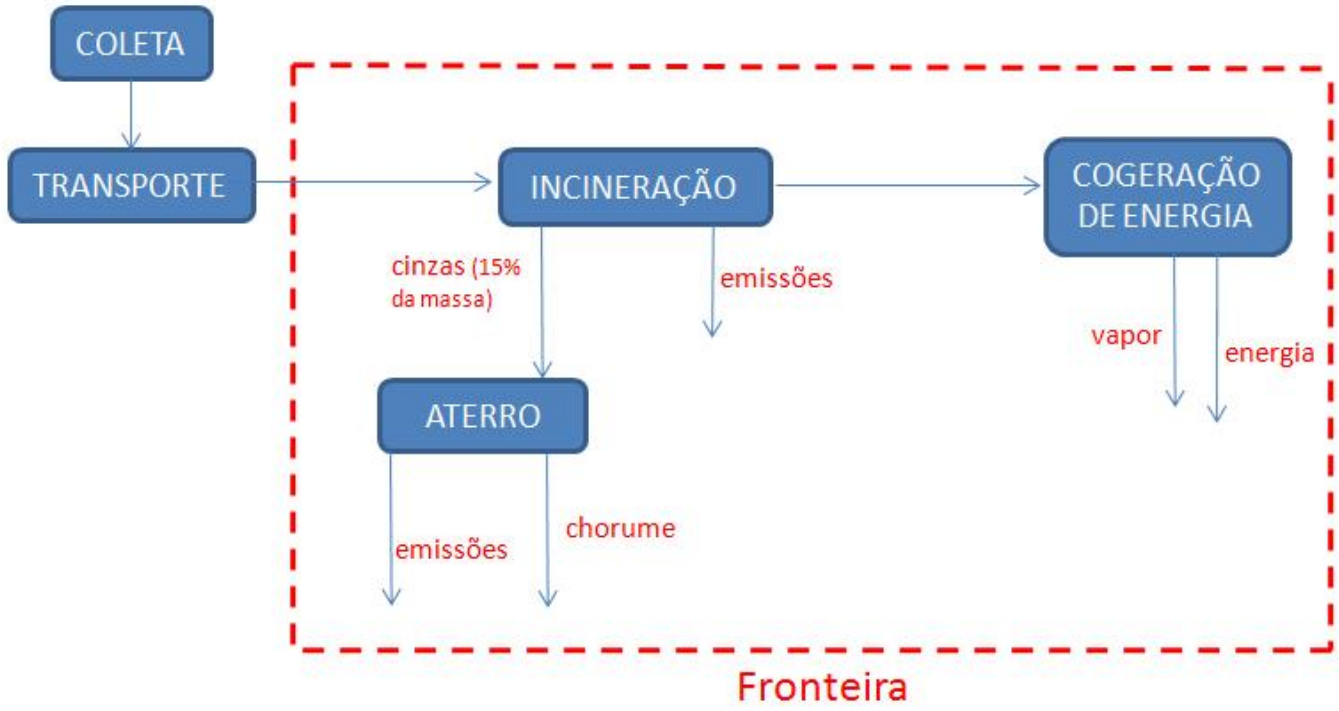

Figura 2. Fluxograma do processo e fronteira do estudo para incineração

O biogás gerado da biodigestão passa por um processo de purificação para remoção do gás metano, que é encaminhado a combustão para geração de energia na unidade de cogeração que utiliza motor com conversor catalítico.

O incinerador apresenta basicamente depósito de resíduos, grelha, caldeira de vapor, precipitador eletrostático e lavador de gases. As cinzas geradas são dispostas em aterro de resíduos contaminados como material inorgânico. O calor gerado durante o processo de incineração é utilizado para geração de energia, pois se trata de uma unidade de cogeração.

No processo de biodigestão, para uma tonelada de resíduos, foi considerado 0,5 tonelada de resíduos orgânicos (50\%), conforme composição gravimétrica dos RSU do Brasil, passíveis de serem biodegradados, sendo a outra metade encaminhada para disposição em aterro sanitário. A biodegradação de 0,5 tonelada de resíduos orgânicos gera $70 \mathrm{~m}^{3}$ de biogás, que após passar pelo processo de purificação resulta em $40 \mathrm{~m}^{3}$ de gás metano. O volume de metano extraído do biogás é encaminhado à unidade de cogeração de energia elétrica, gerando $80 \mathrm{kWh}$ (SOARES, 2014).

A incineração de uma tonelada de resíduos foi considerada geração de $15 \%$ da massa de resíduos do processo (HENRIQUES, 2004). Adotou-se que a cogeração pela incineração dessa massa de resíduos, gera $450 \mathrm{kWh}$, de acordo com MME (2008).

A Figura 3 apresenta os resultados dos impactos considerando as emissões de curto prazo, na qual é possível analisar que a disposição em aterro foi a etapa mais representativa nas categorias de impactos avaliadas, com maiores contribuições na categoria "eutrofização", pelas emissões de nutrientes em corpos de água, em seguida as categorias "ecotoxicidade" e "não carcinigênicos", que podem ser relacionados às contaminações do solo e lençol freático por provável falha no sistema de proteção. 


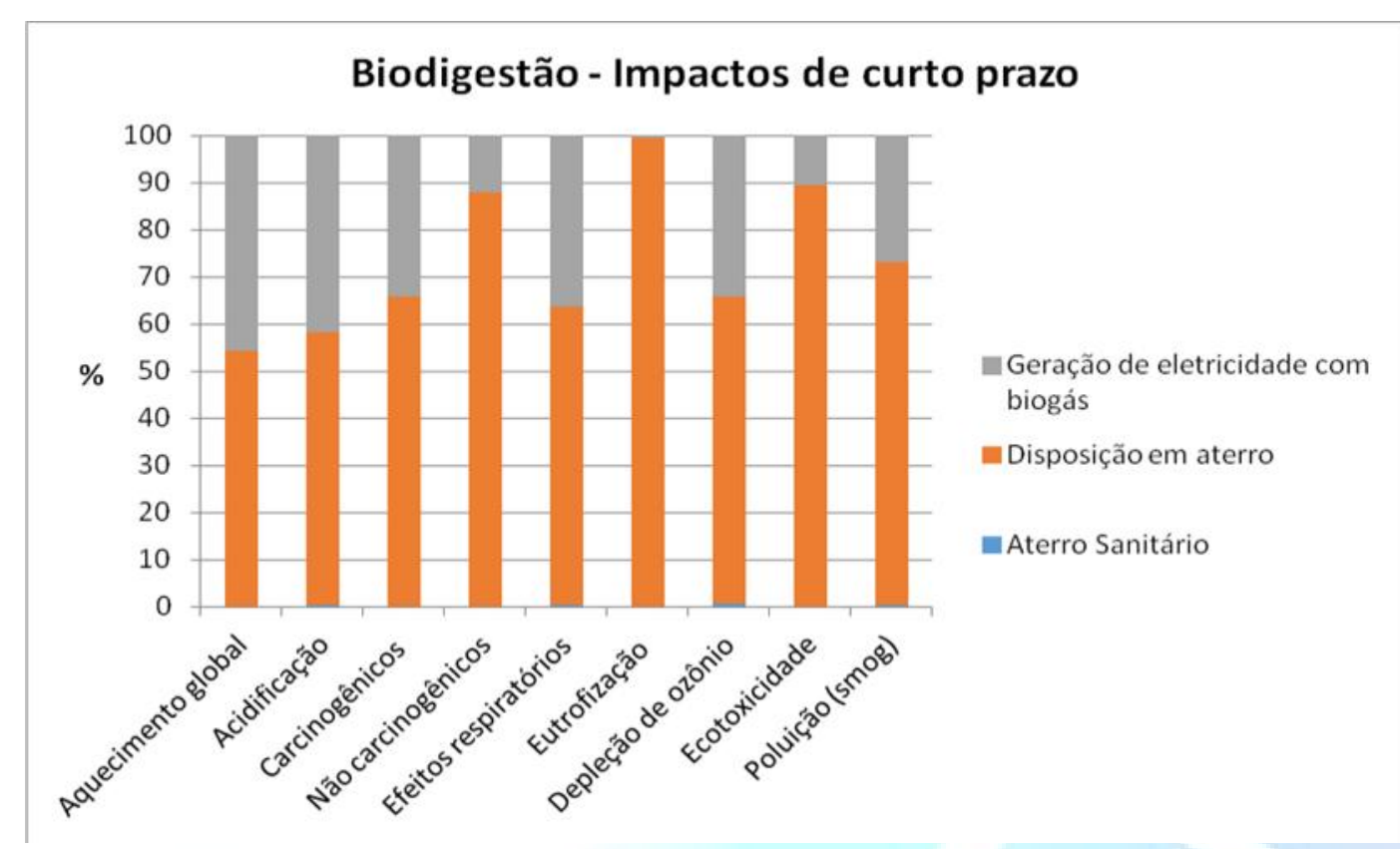

Figura 3. Resultados da ACV por categoria de impacto, para biodigestão em curto prazo.

A Figura 4 mostra a variação dos resultados, considerando os impactos das emissões de longo prazo. A disposição em aterro continua sendo a etapa mais impactante. As maiores contribuições, contudo, estão nas categorias de "carcinogênicos", "não carcinogênicos", "eutrofização" e "ecotoxicidade", impactos que podem ser relacionados às contaminações do solo e lençol freático, por provável falha no sistema de proteção. O aumento desses impactos na etapa de disposição em aterro, quando consideradas as emissões de longo prazo, pode estar relacionado com as emissões de substâncias cumulativas e/ou persistentes, que ao serem emitidas por longo período afetam a saúde humana e os recursos naturais.

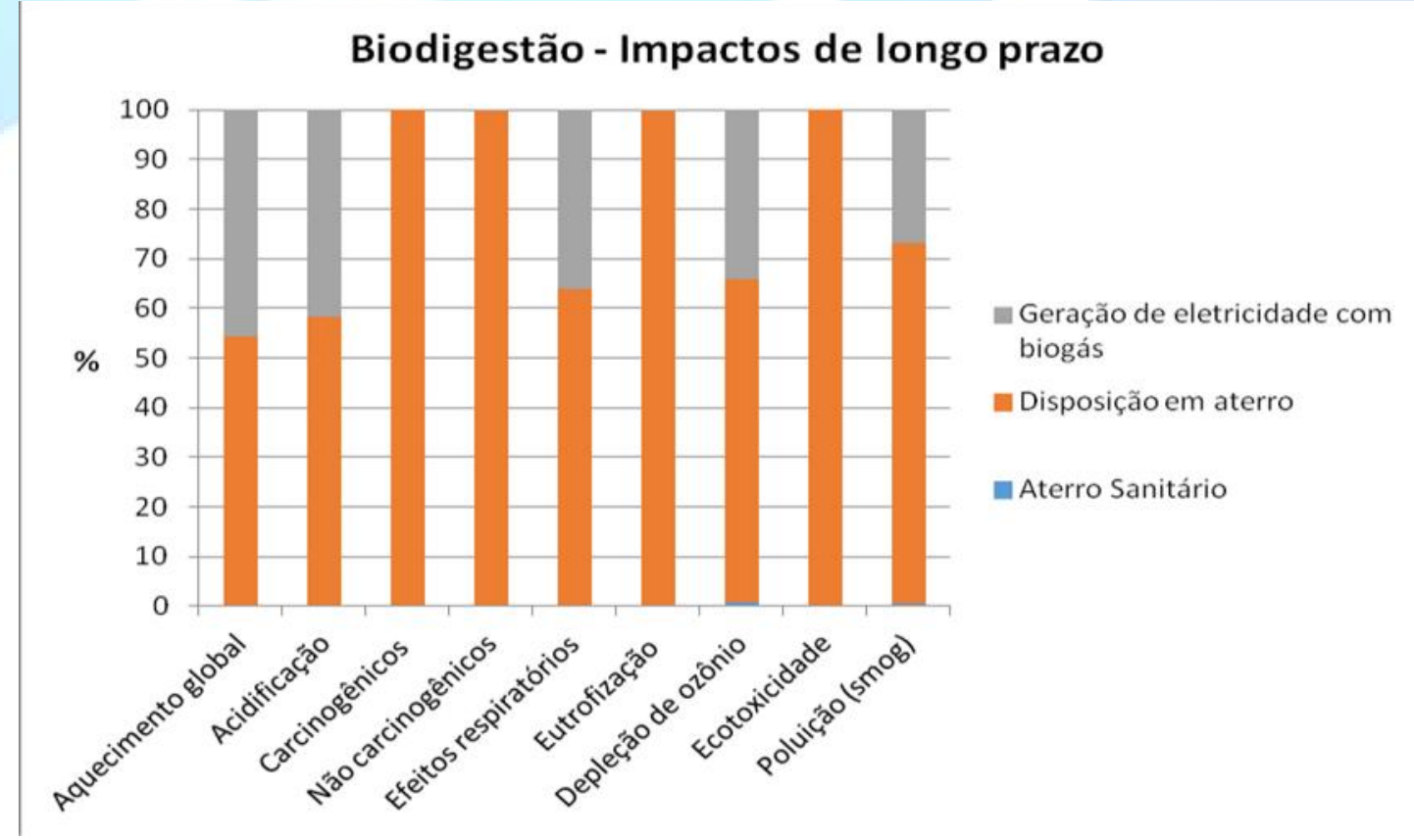

Figura 4. Resultado da ACV por categoria de impacto para biodigestão em longo prazo 
Analisando os resultados em números absolutos, no entanto, nas Tabelas 1 e 2, é possível verificar a atividade que apresenta número mais expressivo. Verifica-se que "não carcinogênico" é a categoria de impacto com número mais expressivo em ambas as análises. Para emissões de curto prazo, o segundo mais representativo é para categoria "aquecimento global", já para as emissões de longo prazo há um aumento considerável em quase todas as categorias, e a segunda mais representativa passa a ser "ecotoxicidade", causando danos à fauna e flora por substâncias tóxicas, e "carcinogênicos" que podem estar associados às substâncias cumulativas e/ou persistentes.

É possível observar também que, em todas as categorias de impacto a etapa que mais contribui é a disposição em aterro, o que está associado a aqueles que podem ocorrer em decorrência das emissões de longo prazo, tendo em vista que os rejeitos depositados nos aterros passam muitos anos em atividades de decomposição, gerando compostos que podem interagir com o meio ambiente, acarretando outros impactos.

Tabela 1 - Resultados para biodigestão - curto prazo

\begin{tabular}{|c|c|c|c|c|c|}
\hline Categoria de impacto & Unidade & $\begin{array}{c}\text { Aterro } \\
\text { Sanitário }\end{array}$ & $\begin{array}{c}\text { Disposição } \\
\text { em aterro }\end{array}$ & $\begin{array}{c}\text { Geração de } \\
\text { eletricidade }\end{array}$ & TOTAL \\
\hline Aquecimento global & $\mathrm{kg} \mathrm{CO}$ eq & 0,0617 & $\mathbf{2 1 , 5}$ & 18,1 & 39,6617 \\
\hline Acidificação & $\mathrm{H}^{+}$mols eq & 0,0214 & 4,33 & 3,13 & 7,4814 \\
\hline Carcinogênicos & $\mathrm{kg}$ benzeno eq & $4,43.10^{-05}$ & 0,022 & 0,0114 & 0,033444 \\
\hline Não carcinogênicos & $\mathrm{kg}$ tolueno eq & 0,227 & $\mathbf{2 1 9 , 0 0}$ & 29,9 & 249,127 \\
\hline Efeitos respiratórios & $\mathrm{kg} \mathrm{PM}^{1} 2.5 \mathrm{eq}$ & $6,96.10^{-05}$ & 0,015 & 0,00854 & 0,02361 \\
\hline Eutrofização & $\mathrm{kg} \mathrm{N}^{2} \mathrm{eq}$ & $4,16.10^{-05}$ & 0,694 & 0,00415 & 0,698192 \\
\hline Depleção de ozônio & $\mathrm{kg} \mathrm{CFC-11^{3 } \mathrm { eq }}$ & $2,23.10^{-08}$ & $1,69.10^{-06}$ & $8,87.10^{-07}$ & $2,6.10^{-06}$ \\
\hline Ecotoxicidade & $\mathrm{kg} 2,4-\mathrm{D}$ eq & 0,00849 & 8,74 & 1,05 & 9,79849 \\
\hline Poluição (smog) & $\mathrm{gNOxeq}$ & 0,000439 & 0,061 & 0,0225 & 0,083939 \\
\hline
\end{tabular}

Tabela 2 - Resultados para biodigestão - longo prazo

\begin{tabular}{|c|c|c|c|c|c|}
\hline Categoria de impacto & Unidade & $\begin{array}{c}\text { Aterro } \\
\text { Sanitário }\end{array}$ & $\begin{array}{c}\text { Disposição } \\
\text { em aterro }\end{array}$ & $\begin{array}{c}\text { Geração de } \\
\text { eletricidade }\end{array}$ & TOTAL \\
\hline Aquecimento global & $\mathrm{kg} \mathrm{CO}$ eq & 0,0617 & 21,5 & 18,1 & 39,7 \\
\hline Acidificação & $\mathrm{H}^{+}$mols eq & 0,0214 & 4,33 & 3,13 & 7,48 \\
\hline Carcinogênicos & $\mathrm{kg}$ benzeno eq & $7,33.10^{-5}$ & $\mathbf{8 7 , 9}$ & 0,0567 & 88 \\
\hline Não carcinogênicos & $\mathrm{kg}$ tolueno eq & 0,686 & $\mathbf{2 , 8 5 . 1 0 ^ { 6 }}$ & 1330 & $2,86.10^{6}$ \\
\hline Efeitos respiratórios & $\mathrm{kgMP} 2.5 \mathrm{eq}$ & $6,9.10^{-5}$ & 0,0151 & 0,00864 & 0,0238 \\
\hline Eutrofização & $\mathrm{kg} \mathrm{N}$ eq & $8,09.10^{-5}$ & 3,39 & 0,0119 & 3,4 \\
\hline Depleção de ozônio & $\mathrm{kg} \mathrm{CFC-11eq}$ & $2,23.10^{-8}$ & $1,69.10^{-6}$ & $8,87.10^{-7}$ & $2,6.10^{-6}$ \\
\hline Ecotoxicidade & $\mathrm{kg} \mathrm{2,4-D} \mathrm{eq}$ & 0,042 & $\mathbf{1 , 9 7 . 1 0 ^ { 4 }}$ & 22,1 & $1,97.10^{4}$ \\
\hline Poluição (smog) & gNOxeq & 0,000439 & 0,061 & 0,0225 & 0,084 \\
\hline
\end{tabular}

\footnotetext{
${ }^{1} \mathrm{MP}$ - Material Particulado

${ }^{2} \mathrm{CFC}-11$ - clorofluorcarboneto: triclorofluormetano

${ }^{3} 2,4-\mathrm{D}$ - ácido diclorofenóxiacético
} 
Em seguida aparece a geração de eletricidade, onde os impactos mais expressivos também são para as categorias "não carcinogênicos", "aquecimento global" e "ecotoxicidade" em curto e longo prazo, contudo, os números são bastante inferiores aos apresentados na etapa de disposição em aterro. O número mais aproximado entre as etapas de disposição em aterro e geração de eletricidade ocorre na categoria de "aquecimento global", e ainda assim, é maior para a "disposição em aterro".

Os impactos da etapa de construção do aterro sanitário são menos expressivos, quando comparados aos demais, isso acontece, pois durante a análise de inventario foi feita uma ponderação, para impacto da instalação da infraestrutura do aterro não fosse todo considerado para a unidade funcional, tendo em vista que o aterro é construído para 30 anos de operação e o impacto de sua instalação deve ser distribuído para todo material a ser depositado.

Já para incineração, os resultados obtidos com os cálculos do software estão apresentados nas Figuras 5 e 6 e nas Tabelas 3 e 4 . A Figura 5 apresenta os impactos para emissões de curto prazo, desta forma, é possível analisar que a própria etapa de incineração foi a mais representativa nas categorias de impactos avaliadas. As maiores contribuições observadas são para a categoria "aquecimento global". Apenas na categoria "depleção de ozônio" a disposição de resíduos do incinerador - cinzas - apresentou-se mais representativa, a qual foi de aproximadamente $45 \%$. A Figura 6 mostra os resultados considerados de longo prazo.

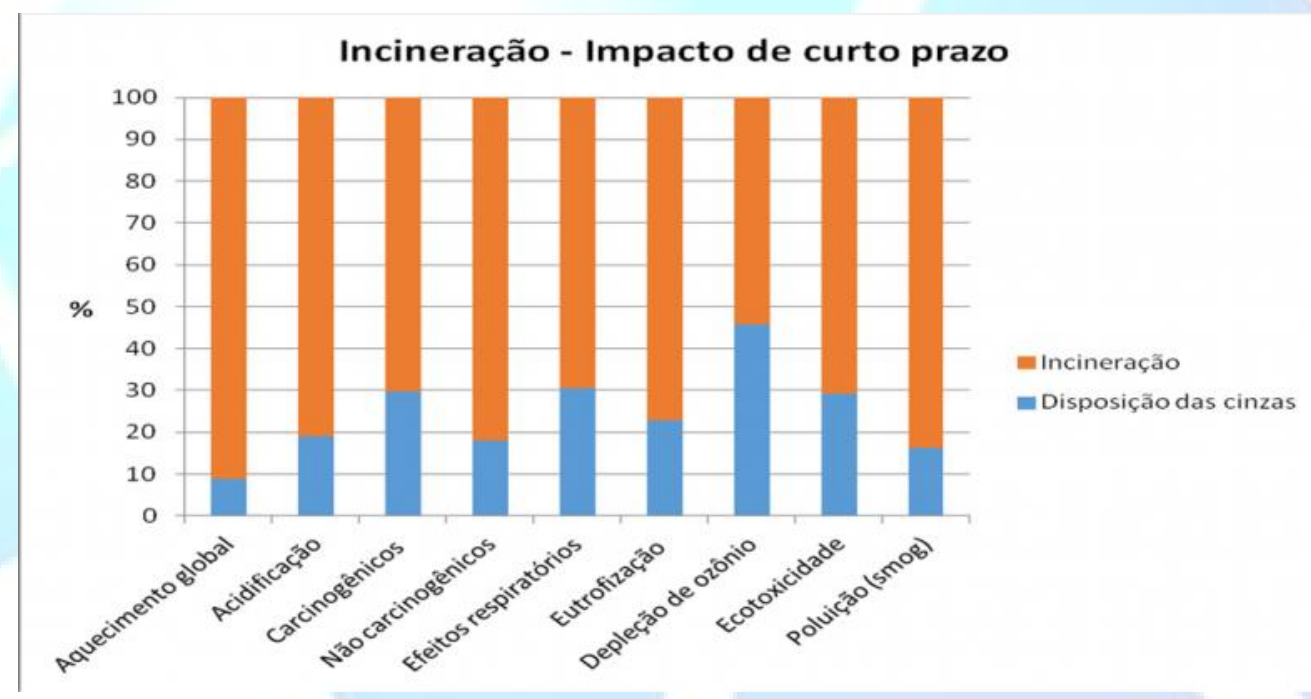

Figura 1. Resultado da ACV por categoria de impacto para incineração em curto prazo 


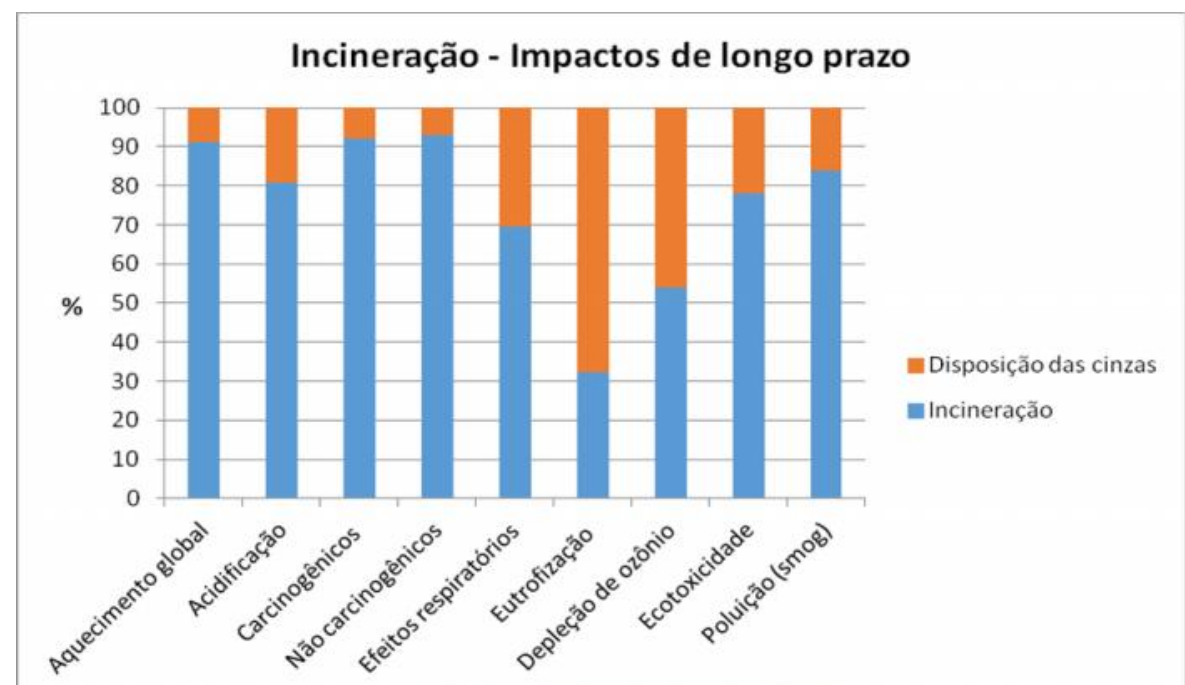

Figura 2. Resultado da ACV por categoria de impacto para incineração em longo prazo

A incineração continua sendo mais impactante, exceto para a categoria "eutrofização", devido às possíveis emissões provenientes do aterro. As maiores contribuições observadas, contudo, são as categorias de "não carcinogênicos", "carcinogênicos", e "aquecimento global", impactos estes que podem ser relacionados às emissões atmosféricas que incluem GEE que contribuem para o aquecimento global e substâncias nocivas à saúde humana.

Analisando os resultados em números absolutos, nas Tabelas 3 e 4, é possível verificar a atividade que mais gera impactos no processo. Verifica-se que o "não carcinogênico" é a categoria de impacto que apresenta número mais expressivo, principalmente na etapa de incineração, que podem representar risco a saúde humana, pois apresentam efeitos toxicológicos.

Os resultados de curto prazo, a segunda categoria com número mais significante é "aquecimento global" seguida pela categoria "ecotoxicidade". Já para impactos de longo prazo, ocorre o inverso, a segunda categoria é "ecotoxicidade" seguida por "aquecimento global". Isto ocorre, pois em longo prazo são contabilizados impactos de substâncias cumulativas e/ou persistente.

Tabela 3 - Resultados para incineração - curto prazo

\begin{tabular}{|c|c|c|c|c|}
\hline Categoria de impacto & Unidade & Incineração & $\begin{array}{r}\text { Disposição } \\
\text { das cinzas }\end{array}$ & TOTAL \\
\hline Aquecimento global & $\mathrm{kg} \mathrm{CO}$ eq & $\mathbf{5 0 5}$ & 49,3 & 554,3 \\
\hline Acidificação & $\mathrm{H}^{+}$mols eq & 23 & 5,44 & 28,44 \\
\hline Carcinogênicos & $\mathrm{kg}$ benzeno eq & 2,5 & 1,06 & 3,56 \\
\hline Não carcinogênicos & $\mathrm{kg}$ tolueno eq & $\mathbf{3 , 0 8 . 1 0}$ & 682 & 3762 \\
\hline Efeitos respiratórios & $\mathrm{kg} \mathrm{PM}^{4} 2.5 \mathrm{eq}$ & 0,0514 & 0,0225 & 0,0739 \\
\hline Eutrofização & $\mathrm{kg} \mathrm{N}$ eq $^{\mathbf{3}}$ & 0,0483 & 0,0143 & 0,0626 \\
\hline Depleção de ozônio & $\mathrm{kg} \mathrm{CFC-11^{5 } \mathrm { eq }}$ & $2,91.10^{-06}$ & $2,46.10^{-06}$ & $5,37.10^{-06}$ \\
\hline Ecotoxicidade & $\mathrm{kg} 2,4-\mathrm{D}^{6} \mathrm{eq}$ & $\mathbf{9 4 , 1 0}$ & 38,8 & 132,9 \\
\hline Poluição (smog) & $\mathrm{gNOxeq}$ & 0,494 & 0,095 & 0,589 \\
\hline
\end{tabular}

\footnotetext{
${ }^{4} \mathrm{MP}$ - Material Particulado

${ }^{5} \mathrm{CFC}-11$ - clorofluorcarboneto: triclorofluormetano

${ }^{6} 2,4-\mathrm{D}$ - ácido diclorofenóxiacético
} 
Tabela 4. Resultados para incineração - longo prazo

\begin{tabular}{|c|c|c|c|c|}
\hline Categoria de impacto & Unidade & Incineração & $\begin{array}{c}\text { Disposição } \\
\text { das cinzas }\end{array}$ & TOTAL \\
\hline Aquecimento global & $\mathrm{kg} \mathrm{CO}_{2} \mathrm{eq}$ & $\mathbf{5 0 5}$ & 49,3 & 554,3 \\
\hline Acidificação & $\mathrm{H}^{+}$mols eq & 23 & 5,44 & 28,44 \\
\hline Carcinogênicos & $\mathrm{kg}$ benzeno eq & 80 & 6,74 & 86,74 \\
\hline Não carcinogênicos & $\mathrm{kg}$ tolueno eq & $\mathbf{2 , 5 . 1 0 ^ { \mathbf { 6 } }}$ & $1,87.10^{5}$ & $2,7.10^{6}$ \\
\hline Efeitos respiratórios & $\mathrm{kg} \mathrm{PM} \mathrm{2.5} \mathrm{eq}$ & 0,0516 & 0,0227 & 0,0743 \\
\hline Eutrofização & $\mathrm{kg} \mathrm{N}$ eq & 1,6 & 3,36 & 4,96 \\
\hline Depleção de ozônio & $\mathrm{kg} \mathrm{CFC-11eq}$ & $2,9.10^{-6}$ & $2,46.10^{-6}$ & $3,36.10^{-6}$ \\
\hline Ecotoxicidade & $\mathrm{kg} 2,4-\mathrm{Deq}$ & $\mathbf{3 , 1 6 . 1 0 ^ { 4 }}$ & $8,85.10^{3}$ & $4,05.10^{4}$ \\
\hline Poluição (smog) & $\mathrm{gNOxeq}$ & 0,494 & 0,095 & 0,589 \\
\hline
\end{tabular}

É possível observar também que, em todas as categorias de impacto a etapa que mais contribui é a própria etapa de incineração, que é principal, pois constitui o processo estudado, o que já era esperado em se tratando do seu potencial de causar impactos ambientais.

Para a etapa de disposição das cinzas em aterro sanitário, os impactos mais expressivos também são para a categoria "não carcinogênicos", "aquecimento global" e "ecotoxicidade". A única categoria de impacto que a disposição das cinzas apresentou-se superior foi para "eutrofização", quando analisado em longo prazo, que pode estar associada aos riscos de contaminação que os aterros apresentam.

Como citado anteriormente, durante a revisão bibliográfica, a ACV é uma ferramenta que permite comparar dois processos. Sendo assim, a Figura 7 apresenta a comparação entre os processos estudados, considerados em curto e longo prazo.

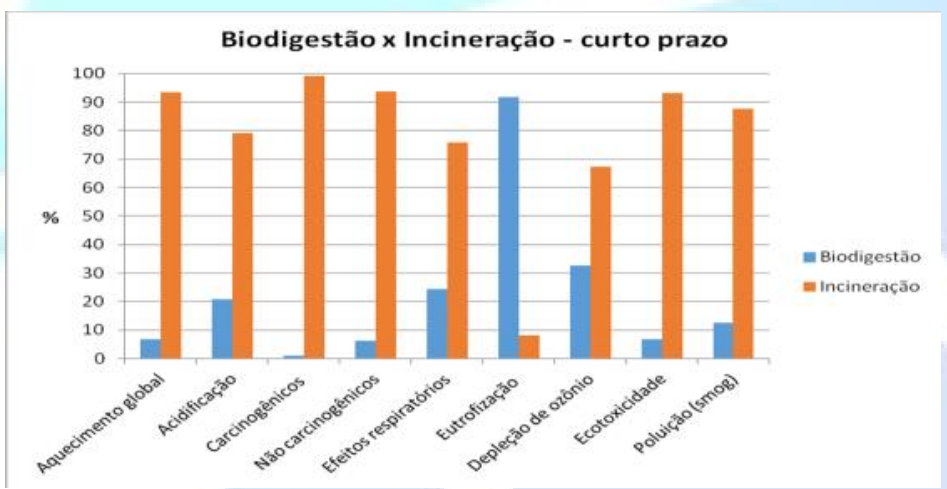

(a)

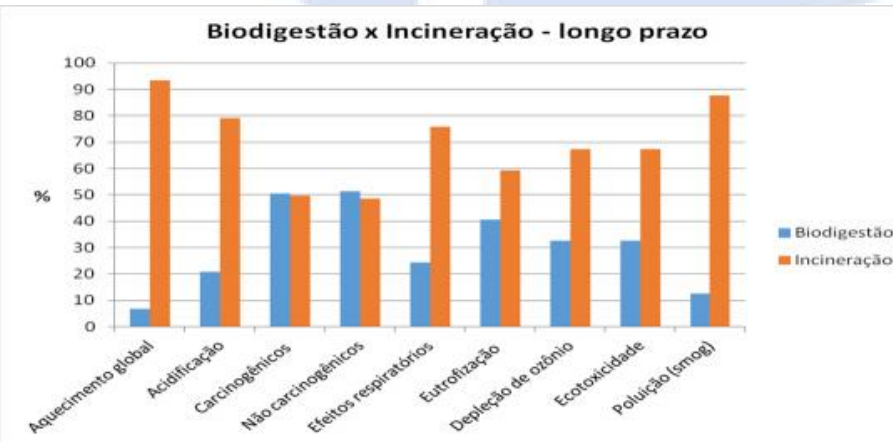

(b)

Figura 3. Comparação biodigestão e incineração - curto prazo (a) e longo prazo(b) 
Os resultados comparativos entre os processos de tratamento de RSU com geração de energia mostram que a incineração é o processo mais impactante. Quando são consideradas as emissões de curto prazo, a única categoria de impacto em que a biodigestão se apresenta mais impactante é a "eutrofização", que pode estar associado às elevadas cargas de nutrientes presentes nos materiais orgânicos processados na biodigestão, bem como seu produto final digerido, composto orgânico, que podem causar eutrofização quando inserido ou disposto inadequadamente em corpos de água.

Analisando os resultados comparativos em longo prazo, é possível verificar que a incineração continua sendo mais impactante que a biodigestão, porém as diferenças se tornam mais sutis, além disso, as categorias "carcinogênico" e "não carcinogênico" ficaram bem aproximadas entre os dois processos, sendo para biodigestão ainda um pouco mais elevado na categoria "não carcinogênico".

A Avaliação do Ciclo de Vida é uma ferramenta importante que permite a avaliação de um produto, processo ou serviço em busca de soluções para problemas ambientais incluindo todas as etapas do ciclo de vida, possibilitando a análise e decisão dentre várias atividades, por aquela com menor impacto ambiental, e ainda permite a identificação de oportunidades de melhoria para o processo estudado, visando a minimização dos impactos ambientais.

Para o processo de biodigestão anaeróbia dos resíduos sólidos urbanos com geração de energia elétrica, a aplicação da ACV permitiu verificar que o impacto que mais expressivo é o da categoria "não carcinogênico", representando risco à saúde humana pelos efeitos toxicológicos. Também foram expressivos os impactos de "aquecimento global", quando analisado os impactos das emissões de curto prazo. Quando considerados os impactos das emissões de longo prazo, observa-se que há um aumento considerável em quase todas as categorias, e que a segunda mais representativa passa a ser "ecotoxicidade" causando por danos à fauna e flora por substâncias tóxicas, seguida dos "carcinogênicos" que pode estar associado às substâncias cumulativas e/ou persistentes.

Observou-se também que, entre as categorias de impacto a etapa que mais contribui é a disposição em aterro, que está associado aos impactos que podem ocorrer em consequência das emissões de longo prazo, tendo em vista que os rejeitos depositados nos aterros passam muitos anos em atividades de decomposição, gerando compostos que podem interagir com o meio ambiente, acarretando nestes impactos.

Para o processo de incineração, verifica-se também que o "não carcinogênico" é a categoria de impacto que apresenta números mais expressivos, que podem representar risco a saúde humana, pois apresentam efeitos toxicológicos. Analisando em curto prazo, a segunda categoria com número mais significante é "aquecimento global" seguida pela categoria "ecotoxicidade". Já para impactos de longo prazo, ocorre o inverso, a segunda categoria é "ecotoxicidade" seguida por "aquecimento global". Isto ocorre, pois em longo prazo são contabilizados os impactos causados por substâncias cumulativas e/ou persistente. É possível observar também que, em todas as categorias de impacto a etapa que mais contribui é a própria etapa de incineração, que constitui o processo estudado, o que já era esperado em se tratando do seu potencial de causar impactos ambientais.

Os resultados comparativos entre os processos de tratamento de RSU com geração de energia mostram que, conforme esperado, a incineração é o processo mais impactante. Quando são consideradas as emissões de curto prazo, a única categoria de impacto em que a biodigestão se apresenta mais impactante é a "eutrofização", que pode estar associado às elevadas cargas de nutrientes presentes nos materiais orgânicos processados na biodigestão, que podem causar eutrofização quando inserido ou disposto inadequadamente em corpos d'água. Analisando os resultados em longo prazo, a incineração continua sendo mais impactante que a biodigestão, porém as diferenças se tornam mais sutis, e as categorias "carcinogênico" e "não carcinogênico" ficaram 
bem aproximadas entre os dois processos, sendo para biodigestão ainda um pouco mais elevado na categoria "não carcinogênico".

Muito embora, os dados não sejam de um cenário especificamente brasileiro, as recomendações de quanto às oportunidades de melhoria no desempenho ambiental dos processos, com base nos resultados obtidos, podem ser aplicadas ao Brasil, uma vez que os processos mais impactantes seriam os mesmos se aqui forem aplicados, alterando muito provavelmente os dados quantitativos com relação as categorias de impacto.

\section{CONCLUSÕES}

A gestão adequada dos resíduos sólidos urbanos orientada à sua utilização energética contribui para reduzir o consumo de combustíveis fósseis e aliviar o impacto ambiental. Neste sentido, este estudo teve o objetivo principal de estudar alternativas de disposição e aproveitamento energético de RSU através da identificação de impactos ambientais e comparação destas alternativas, tendo em vista propor diretrizes relativas aos aspectos ambientais.

Os resultados mostraram que, entre as alternativas consideradas neste estudo, a geração de energia elétrica a partir do processo de tratamento mecânico biológico parece ser mais atraente em termos de impactos ambientais quando comparada a incineração. A princípio, a incineração era vista como uma alternativa ambiental não amigável devido aos impactos ambientais causados; no entanto, as tecnologias vêm se aprimorando nas últimas décadas e, atualmente, a incineração possui tecnologias de ponta que proporcionam confiabilidade à remoção de gases tóxicos, tornando-a também uma opção a ser considerada, e esta pode ser utilizada como complementar ao processo de tratamento mecânico biológico.

Deve-se também considerar, no entanto, que o processo de incineração apresenta maior eficiência energética, gerando com uma tonelada de resíduos $450 \mathrm{kWh}$, enquanto que a biodigestão anaeróbia gera com a mesma massa $80 \mathrm{kWh}$. Sendo assim, se fazem necessários investimentos em tecnologias que possibilitem a redução dos impactos ambientais causados por estas tecnologias, para tornar a incineração numa solução sustentável para tratamento dos RSU associado à geração de energia, pois se mostra mais eficiente tanto para geração de energia, quanto na redução do volume, massa e periculosidade dos resíduos.

Como conclusão geral deste estudo, observou-se a identificação da existência de opções e oportunidades para a implementação de projetos relacionados à geração de energia elétrica no Brasil a partir de resíduos sólidos urbanos, especialmente através do processo combinado de tratamento mecânico biológico e de incineração, com a ressalva de que ainda existem barreiras econômicas, políticas e sociais que precisam ser vencidas. No entanto, as tecnologias apresentadas merecem ser cada vez mais estudadas, viabilizadas e aplicadas, pois oferecem uma disposição, tratamento e aproveitamento energético de resíduos sólidos urbanos mais eficientes e sustentáveis, a exemplo dos países mais desenvolvidos do mundo. Trabalhos futuros são necessários para aprimorar os projetos atualmente realizados.

De forma geral, o eficaz gerenciamento dos resíduos deve ser fundamentado na combinação de diversas tecnologias, buscando atender as demandas e especificidades de cada área e/ou setor. Portanto, recomenda-se a utilização das tecnologias de recuperação energética, tais como, incineração, biodigestão e captação e utilização de biogás de aterros, associados à reciclagem, de forma a integrar seu objetivo principal, de tratamento dos resíduos à geração de energia elétrica.

Sendo assim, os RSU devem deixar de serem tratados apenas como um problema ambiental e passar a serem considerados como alternativa para a geração de energia. Haja vista que, a recuperação energética é hoje uma realidade em outros países e importante alternativa no 
gerenciamento dos RSU, que deve ser considerada pelos municípios quando da elaboração do seu plano de gestão de resíduos, visando um futuro mais sustentável.

\section{REFERÊNCIAS}

ABNT - ASSOCIAÇÃO BRASILEIRA DE NORMAS TÉCNICAS. Gestão Ambiental Avaliação do Ciclo de Vida - Princípios e estrutura: NBR ISSO 14040, Rio de Janeiro: ABNT, 2009. 21p.

Gestão Ambiental - Avaliação do

Ciclo de Vida - Princípios e estrutura: NBR ISSO 14040, Rio de Janeiro: ABNT, 2009 - versão corrigida 2014. 21p.

ACV BRASIL. Simapro. Disponível em: <http://www.acvbrasil.com.br/simapro/>. Acesso em: 17 de Abril de 2014.

ARAÚJO, M.G. Modelo de avaliação do ciclo de vida para a gestão de resíduos de equipamentos eletroeletrônicos no Brasil. 2013. Tese (Doutorado em Planejamento Energético) Universidade Federal do Rio de Janeiro, 2013. 232p.

COSTA, R.C.; PRATES, C.P.T. O papel das fontes renováveis de energia no Desenvolvimento do setor energético e barreiras à sua penetração no mercado. Departamento de Gás, Petróleo, Co-Geração e Outras Fontes de Energia - BNDES, 2005. 26p.

GOMES, F.C.S.P. Biometanização Seca de Resíduos Sólidos Urbanos. Estado da Arte e Análise Crítica das Principais Tecnologias. 2010. Dissertação (Mestrado em Sustentabilidade

Socioeconômica e Ambiental). Universidade Federal de Ouro Preto, Ouro Preto, MG, 2010. 199p.

HENRIQUES, R.M. Aproveitamento energético dos Resíduos Sólidos Urbanos: uma abordagem tecnológica. 2004. Dissertação (Mestrado em Ciências em Planejamento Energético) Universidade Federal do Rio de Janeiro, 2004. 190p.

MARTINS, L.S. Geração de energia através de biomassa. (Projeto de Graduação, Engenharia Elétrica) - Universidade Federal do Espírito Santo, 2006. 83p.

MME - MINISTÉRIO DE MINAS E ENERGIA. Aproveitamento Energético dos Resíduos Sólidos Urbanos de Campo Grande - MS. Série Recursos Energéticos. Rio de Janeiro, 2008. 73p.

MORGADO, T.C.; FERREIRA, O.M. Incineração de resíduos sólidos urbanos, aproveitamento na co-geração de energia. Estudo para a região metropolitana de Goiânia. Universidade Católica de Goiás - Departamento de Engenharia - Engenharia Ambiental - Goiânia, 2006. 18p.

PECORA, V.; VELÁZQUEZ, S.M.S.G.; COELHO, S.T. Aproveitamento do biogás proveniente dos resíduos sólidos urbanos para geração de energia elétrica: estudo de caso em São Paulo. Centro Nacional de Referencia em Biomassa. Disponível em: <http://cenbio.iee.usp.br/download/publicacoes/congbioen_pecora.pdf >. Acesso em: 20 de Abril de 2013. 
SANTOS, G.G.D. Análise e perspectivas de alternativas de destinação dos resíduos sólidos urbanos: o caso da incineração e da disposição em aterros. 2011. Dissertação (Mestrado em Planejamento Energético) - Universidade Federal do Rio de Janeiro, 2011. 193p.

SANTOS, L.M.M. Avaliação ambiental de processos industriais. - Ouro Preto: ETFOP, 2002. $136 \mathrm{p}$.

SOUZA, J.; PELEGRINI, L.; MOTTA, C.A.O.; COELHO, M.A.A.; SCHAEFFER, L. Tratamento de resíduos urbanos, geração de energia e fertilizante: uma perspectiva para a região do Vale dos Sinos. In: Anais do $3^{\circ}$ Congresso Internacional de Tecnologias para o Meio Ambiente - Bento Gonçalves - RS, Brasil, 25 a 27 de Abril de 2012. 24p.

SOARES, F.R. Avaliação Ambiental e Econômica Comparativa de Alternativas Tecnológicas de Tratamento e Disposição de Resíduos Sólidos Urbanos com Reaproveitamento Energético por Meio da Avaliação de Ciclo de Vida. 2014. Tese (Doutorado em Energia) - Universidade Federal do ABC, Santo André. 200p. 